apoplexy. This patient for a fortnight presented no fresh symptoms, then one day he wished to pass a motion, and subsequently to that, or whilst in the act of passing it, he called out to the sister, and was dead in a few minutes; very probably the rupture occurred during the straining at stool. Other patients have suddenly sat up in bed, called out, and fallen back unconscious and died. But in a number of the cases death does not occur quite as rapidly as that. The patients become profoundly unconscious, respiration becomes more and more irregular, and finally it ceases, and yet the pulse goes on beating vigorously. I have met with instances where artificial respiration has been carried on for three or four hours in these cases, the heart beat going on all the time. I think, however, that they are really quite hopeless. It has been suggested that trephining might be done to relieve the tension while artificial respiration was being performed. These cases run a slightly different course from the ordinary cases of cerebral hæmorrhage, in the extraordinary way in which the respiration is arrested and the pulse continues. That is the clinical picture, then, of this group of cases. As I said at the beginning, I think they form a very definite group of cases, characterised by these phenomena: (1) that there is an early seizure followed by (2) a period in which there are no marked symptoms of any kind, perhaps with the exception of some stiffness of the neck, and (3) subsequently there is a fatal seizure.

In some of these cases, as in the last one, optic neuritis is present. I am told that this last patient had optic neuritis in the left eye. Optic neuritis has been described, of course, in a considerable number of cases of cerebral aneurysm. Those are the points of main interest about these cases, and the only thing in addition which I will say about this particular one is that we got as far as hazarding a diagnosis of basilar aneurysm on account of the curious seizure which he had. But at the bedside I could not myself account for his sudden loss of sight; I could not correlate the general weakness of his four limbs with the loss of sight in the right eye. That was due to lack of knowledge on the subject, because it is one of the features which have been described a considerable number of times, and there are two or three specimens in the museum which illustrate pressure on the optic nerve. But the curious thing in this case-showing how different the real thing in clinical medicine is from the artificial things which are sometimes detailed for teaching purposes-is that this man's aneurysm came from his left anterior cerebral, and yet the optic nerve that was involved was that of the right eye. The aneurysm crosses the middle line and apparently presses on the right optic nerve. I fear that you cannot see that in the specimen now, because the part of the optic nerve which was probably pressed on by the aneurysm has been left in the body.

What is the explanation of the two seizures which occur in these cases? One can only hazard a guess, but I think that probably first of all a slight rupture occurs and then a big and fatal rupture; the first seizure is due to a slight rupture and the fatal seizure is due to a second rupture. In this case the brain afforded some evidence of that, and it is the first time $I$ have seen evidence of it, in the fact that all round the optic nerve and on the surface of the base of the brain there was a considerable amount of staining which might have been due to old blood clot which had been absorbed and the recent blood clot covered the whole thing over. In many of these cases the blood clot formed by the final rupture is so extensive and firm that it is only with the greatest difficulty you can find that there actually is aneurysm, only by washing away the clot for a long time that you can find the seat of the hæmorrhage. Another curious thing about this case is that this aneurysm on the anterior cerebral had, on on the one hand, pressed into the brain, although it does not look a big aneurysm, and that it was projecting into the anterior extremity of the lateral ventricle. On opening the ventricle and looking down you can see the sac at its anterior extremity not ruptured, the blood clot in it showing through. So this aneurysm, although it had reached the ventricle, yet when it ruptured it did not rupture into the ventricle but in the way I have described-that is to say, externally, beneath the pia mater.

Those are the main points which I put before you. As regards diagnosis, I doubt very much whether you can diagnose with certainty aneurysm at the base of the brain, but at any rate you can suspect it, and that is what I wanted to bring before you, and I certainly think that the clinical picture I have tried to put before you is one which is true to the condition and is one which will enable you to suspect its existence in a patient.

Now, what is it liable to be confounded with? The condition which it is most likely to be confounded with, as far as my own experience goes, is a purely functional condition. Such a person is often supposed to be neurasthenic. Of course the cases which make the greatest impression upon one are often those where errors have been made, and I remember a case I saw once, the man being a stockbroker who had lost much money on the Stock Exchange and took to drinking. After a drinking bout he had a vague seizure such as I have described, and I saw him a few days afterwards, when there was nothing to be made out except that his extremities were rather weak and that he had some stiffness in his neck and occipital headache. It was thought by some to be obviously a case of neurasthenia; the idea that there was any organic disease was laughed at, because the man was apparently perfectly well. Three or four days after I saw him he sat up suddenly in bed and called out, and then fell back dead. He had one of these aneurysms. That is a most serious mistake, and it is one $I$ want to warn you against making, because occipital headache, extending down the back, stiffness of the neck, and numbness of the extremities are sometimes features of neurasthenia, and therefore you might make the mistake. The absent kneejerks may help you. The other errors of diagnosis are not important. It is not a serious matter to confound aneurysm with tumour or with meningitis or with any other fatal disease. The serious mistake is to confound the disease with a functional one, and that is what you are extremely prone to do, owing to the fact that when you see the patient the probability is that you will not find any very obvious signs, and such signs as may be present require careful investigation for their detection.

\section{AN EXTENSIVE ENTERECTOMY FOR GANGRENE.}

BY ARTHUR E. J. BARKER, F.R.C.S. ENG.,

PROFESSOR OF SURGERY AT UNIVERSITY COLLEGE HOSPITAL MEDICAI SCHOOL AND SURGEON TO THE HOSPITAL; CONSULTING SURGEOY TO THE QUEEY ALFXANDRA MILITARY HOSPITAL,

\section{MILLBAYK, S.W.}

THE following case is one which has had many points of deep interest to myself in its history and treatment and may be as encouraging to others as it has been to me. It illustrates, besides, several of the good features of spinal analgesia in the clearest way. I have a strong conviction that this method of allaying pain was far more suitable to the case in hand than would have been any other general anæsthetic, and that $b y$ employing it some of the great risks commonly run in such operations were avoided.

The patient, a married woman, aged 47 years, who had had no children, had three years ago an attack of inflammation of the right ovary but no other illness. There had, however, been chronic constipation. On Sunday, March 29th last, she had tinned salmon at breakfast and meat-pie at early dinner. At about 2.30 P.M. she was seized with violent pain in the abdomen. During the afternoon she vomited once or twice and brought up undigested food. She had had a small, hard motion on Sunday morning. Confection of senna was taken on Sunday afternoon subsequently to the onset of the pain. The patient was seen at about 9 P.M. on Sunday evening by Dr. J. A. Belcher of Herne Hill and was then in great pain. The abdomen was flaccid but tender on deep pressure in the right iliac fossa. The pulse was 60 and of full volume. The temperature was normal. She was given chlorodyne, 20 minims every four hours. She was seen again by Dr. Belcher at 11 P.y. when the pain was still unrelieved. A quarter of a grain of morphine was given hypodermically. On Monday morning the patient said that she felt better and had had some sleep. The expression was, however, bad and the hands and face were cyanosed. The pulse was small at 130 . The temperature was still normal. 'The abdomen was now much distended and very tender and there was dulness in the right iliac region. The case was regarded as probably one of appendicitis with perforation and I was sent for. 
I first saw the patient at 12.30 P.M. on Monday, 22 hours after the onset of the illness. She was semi-recumbent in bed, cyanosed in face and hands, and looking very ill. At first I could feel no pulse at either wrist but eventually detected a very slight flicker at the right which could not be accurately counted owing to feebleness and apparent intermission. No pulse at all could be made out on the left. The abdomen was greatly distended and tense, mostly in the middle line below the umbilicus, but the distension extended into the right iliac fossa. Here there was distinct loss of resonance, the left and upper part of the abdomen being abnormally tympanic. There was such extreme tenderness that any further examination was impossible. The case did not appear to me altogether like one of appendicitis for several reasons, and rather seemed to suggest an internal strangulation. Preparations were at once made for operation, but under great difficulties. The house was partly dismantled as the inmates were moving. The domestic service was inadequate. But with the help of a nurse hastily summoned we arranged an empty room and secured an operating table and cleansed the patient's abdominal wall. I was glad that with all other necessaries for operation the requisites for spinal analgesia were in my bag as we were so short-handed and the condition of the patient was so extremely desperate as to require an immediate operation or none at all. I punctured in the third lumbar space and injected 5 centigrammes of stovaine and glucose. Analgesia up to the mammæ was rapid and perfect. The muscles of the abdomen became slack and painless in five minutes or less and the patient was much relieved. We could now feel a large swelling nearly in the middle line but more to the right, which was tense and defined and moveable from side to side. It was of about the size of a 12 year old child's head. This determined me to open in the middle line. When this was done from one to two pints of stinking dark turbid fluid gushed out and immediately after I saw black coils of small intestine. These formed a large bundle strangled below by a thick adhesion round the mesentery. The whole bundle was lifted out on the abdominal wall and was seen and smelt to be gangrenous. There appeared to be from 4 to 6 feet of it strangled. As a matter of fact after removal it measured 4 feet 9 inches. In such conditions there was nothing for it but complete excision of the whole bundle of coils. I therefore laid the healthy proximal and distal parts side by side and made a lateral anastomosis, as the distension of the first and contraction of the second forbade end-to-end junction. I then cut away the gangrenous coils in one mass and closed the ends divided and the gap in the mesentery. The abdomen was then mopped of the remaining foul fluid with sterile gauze and closed without any drainage by stitches passing through all coats of the abdominal wall.

The operation lasted one hour and ten minutes, during which the patient felt no pain or sensation except relief of previous distress. Before I left the house the pulse had recovered and was of fair volume at 130 . She expressed herself as much relieved but very thirsty. She was given a cup of tea which she at once brought up. This was the only vomiting which occurred up to the end of the case. There was no headache.

The course of convalescence may be easily summarised. There was no shock after the operation. The pulse and general condition steadily improved; the temperature, taken four-hourly, kept between $100^{\circ}$ and $101^{\circ} \mathrm{F}$. for 11 days. On the twelfth day it rose to $102^{\circ}$ and then steadily fell to normal. The last rise was probably due to a stitch abscess which afforded a little discharge. The wound was dressed on the thirteenth day and was found soundly healed. The stitches were then removed and all came out dry except the one mentioned. The bowels acted daily after the third day and fond was well taken. There were no complications of any kind.

This case seems to deserve some special notice for several reasons. The onset was very like that of an attack of appendicitis accompanied by perforation, and the rapid aggravation of the symptoms, both general and local, looked very like the supervention of general peritonitis. At the same time the absenct of vomiting as the abdomen swelled and became tender while the pulse rapidly rose raised a doubt, as did also the normal temperature. That there was some particularly severe intra-abdominal lesion was clear as the tenderness and swelling were rapidly increasing and the pulse-rate was rising and its tension falling until it had almost gone altogether. The patient's aspect also suggested a very severe lesion, for the general cyanosis was most marked in the face and hands. I suggested to Dr. Belcher that we should probably find an internal strangulation. But it was not until the abdominal walls had become quite flaccid under the spinal analgesia that it became perfectly clear that we had not an appendicitis case before us. This relaxation was as complete as could possibly be, and one could feel the rounded well-defined mass almost in the middle line which could be moved from side to side like an ovarian cyst, and one thought of a twisted ovarian pedicle as a possible cause. This was negatived by the flatness and flaccidity of the abdomen at the onset. But though a strangulation from band was suspected I was not at all prepared for the advanced condition of gangrene which was at once found when the abdomen was opened, considering that the strangulation must have taken place within 22 hours-i.e., between 2.30 P.M. after a solid dinner and 12.30 P.M. the next day, when I saw the patient practically pulseless. The gut was perfectly black and stinking, as was also the large amount of gangrenous fluid which gushed out of the abdomen. The bundle of gut (now in our museum) tied at both ends filled a large pudding bowl. It contained dark fotid blood under great tension, so that the bundle gave the impression of one tense cyst when felt through the abdominal wall.

As to the enterectomy itself it was done in the way I always deal with similar cases, of which I have described several in THE LANCET. I should have resected a larger amount of the proximal bowel but for two reasons. First, I did not know the length of the gangrenous gut in the bundle constricted. It seemed somewhat about 6 feet, but I could not measure it in situ, and it might have been more -it was actually 4 feet 9 inches-and I feared to sacrifice too much of the small intestine. Secondly, the lesion had only recently taken place and one hoped that the proximal part was still unaffected by those very grave changes which ultimately take place in all bowel above the strangulated point. To the eye the proximal part was only slightly distended, and to the touch it was healthy and free from odema and when opened the mucous nembrane looked normal. I therefore used a spot only a few inches above the constriction for the junction with the distal portion which structurally seemed unchanged. Nevertheless, I was uneasy for some days as to whether I had gone high enough up the proximal portion to secure sound tissue for the junction. The result, however, proves that the tissue was sound enough to go through all the processes of repair. The distal portion for about a foot or so below the constriction presented a very interesting appearance such as I have never before seen or known to be described. It was very irregularly constricted, portions being contracted and almost cord-like and portions dilated. Some unusual nerve phenomena must have been present, probably due to pressure by the band; otherwise it seemed to be perfectly normal in texture. No attempt was made to resect the bundle of intestine until the anastomosis had been effected. It simply lay outside the abdomen until the time came to cut it away and to suture the gap in the mesentery. In taking this course no time was lost and extra soiling of the peritoneum was avoided. Nor was any attempt made to cleanse thoroughly the peritoneal cavity before the anastomosis except that by pressure as much foul fluid was squeezed out as possible and the bowels were protected by gauze. When the enterectomy was complete the cavity was swabbed out with gauze as completely as possible, but could only, of course, be regarded as relatively clean. Nevertheless, both the intestinal wounds and the incision in the abdominal wall healed soundly. The stitches in the latter on the thirteenth day came out dry with the exception of one. This supports the view that the peritoneum is able to dispose of much toxic matter if not too severely injured either by the original lesion or by swabbing and irrigation. The latter I very rarely resort to now and mopping is carried out with dry aseptic gauze in the gentlest manner, with due regard to possible pools in the flanks and pelvis, to which fluid would gravitate. In this case the foul fluid appeared to come from all parts of the peritoneal cavity.

As to the anæsthesia, it was perfect from the patient's and 
surgeon's point of view. All pain vanished within a couple of minutes of the spinal injection and the paralysis of motion followed rapidly. The abdominal walls were relaxed and absolutely still, which greatly facilitated operation. There was no increase of shock from the anæsthetic or the operation, and before the patient was off the table, on which she was left for a couple of hours, the pulse was good. Nor was there any consecutive shock later. This is so frequently the case in severe cases operated on under spinal analgesia as strongly to encourage us to employ this method. And although I regard this case as the most striking illustration of its good points that I have seen in over a hundred abdominal operations under spinal analgesia it does not stand alone. Of course the severe shock before the operation due to the acute strangulation of so large a portion of the small intestine might be expected to disappear to a great extent with the release of the latter, and the improvement after this operation was doubtless in part due to this. But it may safely be said that here the form of anæsthesia employed did not add to this shock.

In conclusion, it must not be forgotten that the early diagnosis of the gravity of the condition made by Dr. Belcher and his prompt action contributed, perhaps, more than any other factor in the saving of this patient's life. A letter from Dr. Belcher of a week or two ago describes the patient as now quite well in every respect at the end of six months.

Harley-street, W.

\section{EXOPHTHALMIC GOITRE: A DISCUSSION ON ITS PATHOLOGY AND TREATMENT. ${ }^{1}$}

BY A. GORDON GULLAN, M.D. LOND., M.R.C.P. LoND., F.R.C.S. ENG.,

SENIOR PHYSICIAN TO THF LIVERPOOL STANLEY HOSPITAL AND LECTURER ON CLINICAL MEDICINE, UNIVERSITY OF LIVERPOOL.

THERE are several instructive and noticeable facts to be gathered from the etiology of exophthalmic goitre. Firstly, it mainly affects women between the ages of 16 and 40 years-i.e., at the period of sexual vitality-and is rare before puberty and after the menopause. Of 495 cases compiled by Buschan, only 15 were under the age of ten years and only 31 were over 50 years of age. Of my own cases only one, a girl, aged nine years, was affected before puberty and my oldest patient was aged 47 years. In this respect Graves's disease differs considerably from myxœedema, as that disease, though present at any age, is much more frequent before puberty in the form of cretinism and later in life after the menopause. This disease, too, like myxœdema, is rare in men-only two of my patients were males. Ord and Mackenzie give the proportion as 20 to 1 , which is probably correct, though many writers give a lower ratio.

The disease may occur in members of the same family and, indeed, in several generations. Five of my cases gave a distinct history of several members of their family being affected with the malady. For instance, two patients were sisters, and their brother, who had previously died from " consumption of the bowels," was affected in the same way. This consumption of the bowels may have been the diarrhoea of Graves's disease. Another patient's maternal aunt had been similarly affected; and two other patients had sisters affected with Derbyshire neck (cystic goitre). One of these, a woman, aged 30 years, had two sisters who resembled her in feature and stature; one, aged 28 years, showed early signs of this disease; and the other, aged 33 years, had a large cystic goitre but manifested no other symptoms. I must also mention Oesterreicher's well-known case, where a woman had 10 children, eight of whom suffered from exopthalmic goitre, and one of the latter had three children similarly affected. ${ }^{2}$

The illness is often consequent upon fright, mental shock, worry, or prolonged mental strain ; or appears to date from an acute illness such as inflnenza. Thus in my cases one patient dated her illness " to a fright whilst pregnant;"

1 A paper read before tho Liverpool Medical Institution on March 12th, 1908, at a discussion on Tixophthalmic Cioitro. Allbutt's System of Medicine, vol. iv., p. 489 another "to worry over a tobacconist business ;" a third " to a family worry, her husband being out of work;" and three others give "worry over family matters" as the cause. The acute symptoms in another case, a nurse, followed an operation for acute appendicitis and the development of a patch of phthisis in her right lung, but some exophthalmos had been noticed in a slight degree for some months previously. This patient's sister also suffers from marked Graves's disease. The remainder of my cases gave no definite cause for the disease and stated that it came on gradually, generally saying that one or other prominent symptom developed some time before the rest. Intense grief and profound emotional disturbance have long been recognised as the cause of an acute attack, but it appears to me that in most, if not all, the instances where worry or fright is stated as the cause, these mental conditions are really post hoc and not ante hoc. I mean that the disease was present, perhaps in a latent or mild degree, at any rate in so slight a degree that the patient was not aware of its presence, before that mental strain occurred, and then owing to the nervous temperament, which is one of the strong characteristic conditions of the disease, she succumbed to the "worry or fright" in an abnormal degree, and consequently dates the onset of her illness from that time. In the case of the nurse mentioned above, I am confident that for some time before her mental shock some degree of Graves's disease was present. Quinsy has been mentioned as an antecedent. I have seen it present in several of my cases during the illness.

We must now turn to the interesting and debateable field of the pathology of this disease. The thyroid gland from a case of exophthalmic goitre shows marked changes, the cells have become columnar instead of cubical, the vesicles stellate instead of square or rounded, and a mucous substance instead of a colloid fills those vesicles. Mr. Walter Edmunds, after removing the greater part of the thyroid from a dog, found that the small part which he had left underwent changes of the nature of a compensatory hypertrophy, which is practically indistinguishable in its features from those I have just described. ${ }^{3}$ These facts are strongly suggestive that the goitrous change of this disease is due to a true hypertrophy which produces an increase of the specific secretions. Furthermore, in support of this view is the strong similarity of exophthalmic goitre to the symptoms of thyroidism, or hyperthyroidism, produced experimentally in animals, or by over-dosage of thyroid extract in man. $\mathrm{Mr}$. Edmunds has again rendered valuable aid to our knowledge of the pathology of Graves's disease by showing that if monkeys or dogs are fed with large doses of thyroid there results accelerated action of the heart, increased metabolism, loss of weight, increased action of the skin, and sometimes marked exophthalmos; indeed, all the symptoms of Graves's disease, including exophthalmos, can be produced in animals by the administration of large doses of thyroid gland. All these symptoms, with the exception perhaps of the exophthalmos, are produced in man by the excessive administration of thyroid, and are not infrequently seen when treating myxodema. A patient of mine, a cretin became irritable and fretful, with rapid action of the heart, raised temperature, moist warm skin, and flushing of her face when the dose of thyroid extract was raised to 12 grains per diem; all the symptoms quickly subsided on the withdrawal of that drug.

Again, in support of the contention that the disease is due to excessive activity of the thyroid (thyroidism) is the fact that the manifestations of exophthalmic goitre are the exact opposite to those of myxœedema, which disease is undoubtedly due to a deficiency of thyroid secretion (athyroidism). The low ebb of metabolism in myxcedema is clearly indicated by the infrequent low tension pulse, feeble cardiac action, mental and physical hebetude, subnormal temperature, dro swollen skin, constipation, diminution of the excretion of urea, and increase in body-weight. Whereas excessive metahnlism is shown in exophthalmic goitre by the frequent raised tension pulse, accentuated action of heart, mental and physical condition active and alert, temperature inclined to be raised, moist skin, looseness of the bowels, increased excretion of nrea, and loss of body weight. How the thyroid socretion modifies metabolism is still rather doubtful. I certainly has an action on bodily growth, as shown by its 